Article

\title{
Effects of Turning Parameters and Parametric Optimization of the Cutting Forces in Machining SiCp/Al 45 wt\% Composite
}

\author{
Rashid Ali Laghari ${ }^{1}$, Jianguang $\mathrm{Li}^{1}$ and Mozammel Mia ${ }^{2, *(\mathbb{D}}$ \\ 1 School of Mechatronics Engineering, Harbin Institute of Technology, Harbin 150001, China; \\ rashidalilaghari@gmail.com (R.A.L.); mejgli@hit.edu.cn (J.L.) \\ 2 Department of Mechanical Engineering, Imperial College London, Exhibition Road, London SW7 2AZ, UK \\ * Correspondence: m.mia19@imperial.ac.uk
}

Received: 30 April 2020; Accepted: 20 June 2020; Published: 24 June 2020

check for updates

\begin{abstract}
Cutting force in the machining process of $\mathrm{SiCp} / \mathrm{Al}$ particle reinforced metal matrix composite is affected by several factors. Obtaining an effective mathematical model for the cutting force is challenging. In that respect, the second-order model of cutting force has been established by response surface methodology (RSM) in this study, with different cutting parameters, such as cutting speed, feed rate, and depth of cut. The optimized mathematical model has been developed to analyze the effect of actual processing conditions on the generation of cutting force for the turning process of $\mathrm{SiCp} / \mathrm{Al}$ composite. The results show that the predicted parameters by the RSM are in close agreement with experimental results with minimal error percentage. Quantitative evaluation by using analysis of variance (ANOVA), main effects plot, interactive effect, residual analysis, and optimization of cutting forces using the desirability function was performed. It has been found that the higher depth of cut, followed by feed rate, increases the cutting force. Higher cutting speed shows a positive response by reducing the cutting force. The predicted and experimental results for the model of $\mathrm{SiCp} / \mathrm{Al}$ components have been compared to the cutting force of $\mathrm{SiCp} / \mathrm{Al} 45 \mathrm{wt} \%$ - the error has been found low showing a good agreement.
\end{abstract}

Keywords: $\mathrm{SiCp} / \mathrm{Al}$ metal matrix composite; cutting force; response surface methodology; turning process; mathematical modeling

\section{Introduction}

Metal matrix composites (MMCs) are a kind of composite materials, which is one of the pioneers of the modern key industrial heavy-duty parts and products for nearly 30 years. The MMCs are replacing many conventional materials due to its possession of excellent mechanical properties. The MMC materials are known for such high tensile strength, wear resistance, high thermal expansion, high hardness, good dimensional stability, and higher weight ratio [1,2]. Aluminum metal matrix composite materials have wide application prospects in transportation, aviation, aerospace, medical industries, including many other important areas of different structural applications [3,4].

MMCs falls under the difficult-to-machine composite materials family. The signs that hinder the wider applications of the MMCs in the industrial sector, include serious tool wear, bad surface quality, issues related to the dimensional accuracy of component, etc. [5,6]. The researchers put more efforts in sorting out such kind of hindrances-different kinds of cutting tool material were introduced along with suitable machining operations to fulfill the gap. Such types of tools include polycrystalline diamond 
(PCD), carbide tools, cemented carbide, high speed steel (HSS) cutting tools, polycrystalline cubic born nitride (PCBN) $[7,8]$. The matrix phases of metal matrix composite materials consist of SiC particles, $\mathrm{Al}_{2} \mathrm{O}_{3}$, magnesium, aluminum metal, and titanium. Although the mechanical properties of SiC-reinforced aluminum-based $\mathrm{SiCp} / \mathrm{A} 1$ composite materials are difficult to match with continuous fiber composites, they are the most competitive due to stable processability, efficient preparation technology. Moreover, their low cost is hugely advantageous for promotion $[9,10]$.

Metal-based composite parts and profiles of various complex shapes, with precision controlling of dimensions, can be manufactured by relying solely on material forming technology. However, it is imperative to provide the subsequent machining in need as a secondary processing technology, in order to further promote the development and practicality of new materials for precise dimensions requirements [10-12].

The machining process of $\mathrm{SiCp} / \mathrm{Al}$ is considered tough in several machining operations and techniques due to the strengthening effect of the reinforcement and the irregular distribution of the high hardness $\mathrm{SiC}$ particles and their volumes. The SiCp/A1 composite material causes sudden breakage of the cutting tool and its rapid wear in the machining process. Such phenomena increase the processing cost and reduces the surface finish of the components [12-15].

Davim and Baptista [15] performed the processing experiments on $\mathrm{SiCp} / \mathrm{Al}$ with different percentages of $\mathrm{SiC}$ particles (7\% and $4 \%$ ) to measure the relationship between cutting force and tool wear in both turning and drilling processes. The measured results from the experiment disclosed that the depth of cut and feed force were shown to be important parameters for both cutting force and tool wear. Subramanian et al. [16] also found a similar observation in the machining and optimization process of MMCs through response surface methodology. The most crucial part of the study was that the Response surface methodology (RSM) provided more convincing outcomes in understanding the behavior of machining parameters. Similarly, Jeyakumar et al. [14] measured the impact of different process parameters on cutting force, surface roughness, and wear mechanism of the cutting tool in the machining operation of Al6061/SiC materials using response surface methodology. Agarwal et al. [17] also conducted a comparative analysis of two commonly used processing performance evaluation methods namely response surface methodology and Taguchi method. The results showed that the response surface methodology had a stronger prediction ability for the interaction terms and squared terms of the machining parameter. The response surface methodology also holds the ability to establish the response model of the significant influence terms and the three-dimensional (3D) response surface, which are not possible with the Taguchi method. Kannan et al. [18] found that the plastic deformation of the matrix material had an important influence on the cutting force.

Tamang and Chandrasekaran [19] examined the tool wear and surface roughness in the machining of $\mathrm{SiCp} / \mathrm{Al}$ reinforced metal matrix composites using coated carbide tools. The spindle speed, feed rate, cutting angle, volume percentage of reinforcing material, etc. were taken as research parameters. Artificial neural network (ANN) and RSM-two modeling techniques-were applied to establish a mathematical model and optimize the process parameters. The results revealed that the models had an improved performance. In some research work, it has been seen that the tool wear had a greater impact on the increasing weight percentage of $\mathrm{SiC}$ particles. It has been found in the wear phenomena of polycrystalline diamond tools when processing composites with $10 \%$ and $20 \% \mathrm{SiC}$ particles reinforced metal matrix composites. As a result, the tool wear increased with the increase of the reinforcement percentage. The tool wear was found more for $20 \%$ particle reinforcement ratio compared to $10 \%$. However, there were no signs of an abnormal rise in cutting forces with different parameters [20]. Similarly, Dabade et al. [21] validated the influence of increasing weight percentage of $\mathrm{SiC}$ particles on cutting force, while performing the cutting experiments of $\mathrm{SiCp} / \mathrm{Al}$ composites along with different weight percentages of $\mathrm{SiC}$ particles. The results of the cutting experiments show that the main factors affecting cutting force depend on the 
different weight percentages of the reinforcement phase of the SiCp/Al. Furthermore, the studies of the effects of cutting parameters and material parameters on the cutting force magnitude and fluctuation are systematically studied in combination with the evolution of the chip morphology of SiC. The variation of the cutting force of the $\mathrm{SiCp} / \mathrm{Al}$ composite material has been related to the number of particles in the chip-to-chip contact area. As the particle size increased, the cutting force fluctuated; as the feed rate and cutting speed increased, the cutting force fluctuated [22].

In the machining process, the force needed to complete the cutting process to cut the workpiece and deform the materials to produce the chips is called the cutting force. The cutting forces have been proven to be the most effective parameter for understanding the machining process of metals. There are three kinds of forces produced in the cutting process, i.e., the feed force, tangential and radial component, when cutting tool's friction, extrusion, and shear on the component materials [23,24]. The machining angle of the cutting tool and parameters will directly influence the cutting force [25,26]. After the tool wears, the effect between the tool and the material changes, and this change is reflected in the cutting force. Therefore, the characteristics related to difficult-to-machine composite materials can be extracted by analyzing the cutting force. It rarely focusses on cutting force trends to observe the machining characteristics of high volume $\mathrm{SiCp} / \mathrm{Al}[27]$.

In this paper, the RSM based box-Behnken design method has been used for the experimental planning and for developing mathematical modeling of cutting force of $\mathrm{SiCp} / \mathrm{Al}$ composite materials for the turning process. The purpose of this study is to explore and investigate the impact of machining parameters on the cutting force in turning process of difficult-to-cut hard material SiCp/Al $45 \mathrm{wt} \%$ reinforced metal matrix composite. Individual effect evaluation using main effect plots, residual plots, and contours plots of cutting forces were developed to analyze and observe the effect of the chosen parameters of the machining process. The predicted and experimental results of the model of $\mathrm{SiCp} / \mathrm{Al}$ components were compared and checked. Finally, the cutting force for $\mathrm{SiCp} / \mathrm{Al} 45 \mathrm{wt} \%$ was calculated with the error percentages, which has also been analyzed and compared.

\section{Materials and Methods}

\subsection{Experimental Conditions}

An experimental study of the turning process of $\mathrm{SiCp} / \mathrm{Al}$ containing $45 \mathrm{wt} \%$ of $\mathrm{SiC}$ reinforced particles has been carried out to observe the cutting force behavior with different machining parameters. To obtain the cutting force model, it is necessary to determine the experimental orthogonal relationship between the process parameters and the cutting force. In this experiment, three different responsive machining parameters such as cutting speed, feed rate and depth of cut have been employed orthogonally. The composite materials work-piece sample had a length of $98.9 \mathrm{~mm}$ and a diameter of $48.2 \mathrm{~mm}$. The cutting force has been recorded for each cutting operation until all the number of cutting operations is completed. A total of 16 sets of cutting operations has been performed. The SiCp/Al composite has been turned by dry-cutting condition. The three-way force has been measured during the experiment. The installation method of each device has been shown in the Figure 1. The dynamometer has been mounted on a self-made T-clamp. The tool has been mounted on a dynamometer with a simple tool holder. The cutting force has been measured by a Kistler 9257B desktop dynamic strain gauge, and the maximum allowable range is $5000 \mathrm{~N}$. According to ISO 3685 (ISO, 1993), an average experimental tool wear standard is $\mathrm{VB}=0.3 \mathrm{~mm}[28,29]$. The experimental setup for turning operation on $\mathrm{SiCp} / \mathrm{Al}$ is shown in Figure 1. Table 1 shows the levels of selected cutting parameters for the turning operation. 


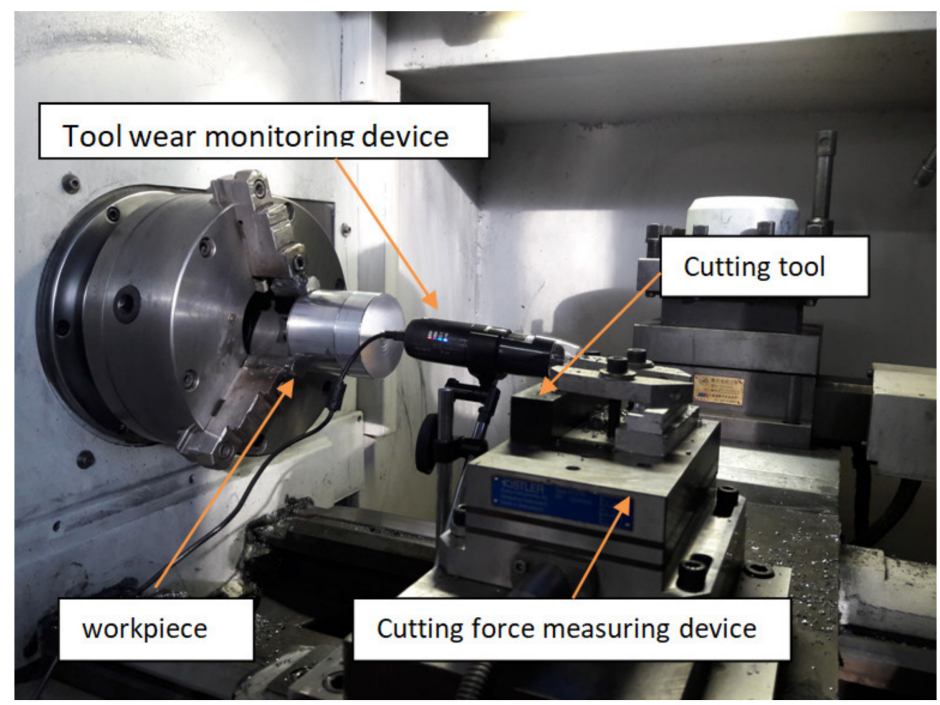

Figure 1. Experimental setup.

Table 1. Cutting Parameters for Cutting Force SiCp/Al $45 \mathrm{wt} \%$.

\begin{tabular}{ccccc}
\hline \multirow{2}{*}{ Cutting Parameters } & \multicolumn{4}{c}{ Levels } \\
\cline { 2 - 5 } & First Level & Second Level & Third Level & Fourth Level \\
\hline Cutting Speed $(\mathrm{m} / \mathrm{min})$ & 6.283 & 12.566 & 18.85 & 25.133 \\
\hline Feed rate $(\mathrm{mm} / \mathrm{rev})$ & 0.01 & 0.015 & 0.02 & 0.025 \\
\hline Depth of cut $(\mathrm{mm})$ & 0.2 & 0.5 & 1 & 1.5 \\
\hline
\end{tabular}

\subsection{Response Surface Methodology (RSM)}

RSM is based on the reasonable experimental design to analyze the experimental data sets for the required respective response. The multivariate quadratic regression equation is used to fit the functional relationship between each factor and the response result so that the optimal parameter combination is acquired from the mathematical model of response surface methodology [30,31]. The influence of turning parameters such as cutting speed, feed rate, and depth of cut on cutting force is a relatively complex nonlinear relationship, so the fitting is presented in Equation (1). The comprehensive influence of each machining parameter on cutting force was obtained as shown in the figure.

The first step for the development of the optimization model in the RSM approach and their respective design for the experimental observation is represented in Equation (1).

$$
Y=F\left[v_{c}, f, a_{p}\right]
$$

An optimization model of $Y$ appears as the desired function, $F$ is the response function, the other parameters $v_{\mathcal{c}} f$, and $a_{p}$, are the cutting speed, feed rate, depth of cut respectively. Quadratic model for $Y$ is written as shown in Equation (2).

$$
Y=a_{0}+\sum a_{i} X_{i}+\sum a_{i j} X_{i}^{2}+\sum a_{i j} X_{i} X_{j}
$$

The number of parameters which are given in Equation (2) can be defined such as, $a_{0}$ constant, $a_{i}, a_{i i}$, and $a_{i j}$ represent the coefficient of linear, quadratic and cross product terms respectively. $X_{i}$ shows the variables which correspond to the studied machining parameters. 


\subsection{Desirability Function Optimization}

In the composite desirability, the target set of optimizations is usually to maximize and minimize the response. It can be defined as the weighted geometric average of the individual expected values of each response. To optimize the targeted responses, the researchers uses different software for optimization, in this study Minitab-17 is employed. This method is used to optimize different responses and predict the optimal combination of parameters. The optimizer searches for combinations of input variables that jointly optimize a set of responses by satisfying the requirements of each response in the set [32]. Optimization is achieved by obtaining the expected value of a single response. The desirability function is the expected value of each response scale to the 0 to 1 desirability scale. The order of each response is from the least ideal to the most ideal. The single expected value is combined to obtain the composite expected value. The obtained composite desirability value is maximized, and the optimal input variable setting is determined. This study contains three responses of cutting force that need to be minimized-the goal is achieved by simultaneously minimizing the factors. However, the mixture of one or more targets is optimized by numerical optimization, where the potential target can be, minimized, maximized target, on the range, and exact value.

The setting of each value for the optimization in desirability function optimization is given as the lower, upper and target values, which are needed to be set according to response requirements. Each response possesses the regression equation, which is used for response optimization and generates the optimization plots for respective response at some scale of the desirability in between range from 0 to 1 desirability scale.

\section{Result and Discussion}

\subsection{Experimental Data of Cutting Forces}

The existing composite machining literature shows that the research and analysis of cutting forces related to turning are mostly carried out from the aspects of cutting speed, feed rate and depth of cut. The influence of cutting force trends on cutting performance of $\mathrm{SiCp} / \mathrm{Al}$ composite materials determines the necessity of analyzing the parameters in this study. Three research variables are selected which are further divided into four levels. In summary, the survey factors and their responses are shown in Tables 1 and 2. It was found that the three processing parameters of cutting speed, feed rate and depth of cut have an influence on the processing response. Therefore, to better understand the processing phenomenon, it is necessary to study the effects of these three elements on cutting force by employing RSM on experimental data for further investigation. The obtained experimental data from the turning process of $\mathrm{SiCp} / \mathrm{Al}$ are given in Table 2 along with details of the cutting parameters and their effects on the cutting force.

\subsection{Effects of Cutting Parameters on Cutting Forces}

In the turning process of $\mathrm{SiCp} / \mathrm{Al}$, the increasing phenomena can be observed in cutting force with increasing depth of cut followed by feed rate, while cutting force reduced with increase in cutting speed-It is reported by different studies in [14-16,33-35]. In MMCs machining process, the built-up-edge (BUE) is also unwanted. BUE can be reduced with slightly increasing cutting speed, this phenomenon can provide ease of removing material in the turning process at lower cutting force. It is also seen that the more increments in feed rate along the higher cutting force is due to the increase of the contact area between workpiece and cutting tool—such a phenomenon was reported by [36].

In the conventional machining process of $\mathrm{SiCp} / \mathrm{Al}$ composite material, the behavior of the cutting force mainly depends on the $\mathrm{SiC}$ particle size, volume, and concentration, as well as the strength of interface bond [16,37]. The increase in cutting speed leads to a decrease in cutting force. It is possible because of increments in cutting temperature in the shear plane region leads to the plastic softening of the machined 
surface, which reduces the shear strength of the $\mathrm{SiCp} / \mathrm{Al}$ composite material. This becomes the trend of cutting force in the cutting process, which indicates that the cutting force reduces with the increase of machining speed $[14,38]$. Some research work mentioned that the cutting force possesses an increasing tendency with increasing $\mathrm{wt}_{\mathrm{t}} \%$ of $\mathrm{SiC}$ particles, while decreases in $\mathrm{SiCp} w \mathrm{t} \%$ showed the cutting force trend to be reduced [15,39]. In all three cutting forces, the increasing evidence was found due to a higher depth of cut, it is because the contact area of component increased in cutting process, which is also higher with the material removal process. It is seen experimentally that the higher depth of cut and feed rate produce more impact, as compared to the $\mathrm{SiCp} w \mathrm{t} \%$ for increasing the cutting force $[39,40]$.

Table 2. The machining parameters and experimental data of cutting force, $F_{x}, F_{y}, F_{z}$ obtained in turning process of $\mathrm{SiCp} / \mathrm{Al} 45 \%$ wt.

\begin{tabular}{ccccccc}
\hline S: No & Cutting Speed $(\mathbf{m} / \mathbf{m i n})$ & Feed Rate $(\mathbf{m m} / \mathbf{r e v})$ & Depth of Cut $(\mathbf{m m})$ & $\boldsymbol{F}_{\boldsymbol{x}}$ Force $(\mathbf{N})$ & $\boldsymbol{F}_{\boldsymbol{y}}$ Force $(\mathbf{N})$ & $\boldsymbol{F}_{\boldsymbol{z}}$ Force $(\mathbf{N})$ \\
\hline 1 & 6.283 & 0.01 & 0.2 & 74.13 & 170.01 & 79.98 \\
2 & 6.283 & 0.015 & 0.5 & 134.01 & 249.9 & 138.23 \\
3 & 6.283 & 0.02 & 1 & 261.09 & 295.03 & 199.81 \\
4 & 6.283 & 0.025 & 1.5 & 375.29 & 385.11 & 275.12 \\
5 & 12.566 & 0.01 & 0.5 & 143.11 & 250.07 & 126.06 \\
6 & 12.566 & 0.015 & 0.2 & 84.33 & 231.96 & 96.11 \\
7 & 12.566 & 0.025 & 1.5 & 409.98 & 319.99 & 289.88 \\
8 & 12.566 & 0.01 & 1 & 290.11 & 315.06 & 221.02 \\
9 & 18.85 & 0.015 & 1.5 & 274.42 & 317.1 & 171.3 \\
10 & 18.85 & 0.02 & 0.2 & 519.8 & 364.89 & 311.05 \\
11 & 18.85 & 0.025 & 0.5 & 69.01 & 214.87 & 86.42 \\
12 & 18.85 & 0.01 & 1.5 & 169.04 & 293.15 & 149.79 \\
13 & 25.133 & 0.015 & 0.5 & 529.98 & 355.23 & 278.31 \\
14 & 25.133 & 0.02 & 0.2 & 149.97 & 261.01 & 207.04 \\
15 & 25.133 & 0.025 & 89.96 & 256.96 & 135.61 \\
16 & 25.133 & & & & 104.97 \\
\hline
\end{tabular}

As the amount of cutting speed increases along with the lower depth of cut, the built-up edge reduces as well as the cutting force reduces. It is also associated with the higher cutting temperature produced in the cutting zone during the cutting operation, which reduces the component yield strength and thickness of the manufactured chips. The lower cutting speed with increasing depth of cut fluctuated the cutting force and produced fractured chips, as well as built edge is formed. In the case of a change in feed rate, it is found that the cutting force linearly varies [33,34,41].

In the machining process, the cutting parameter feed rate also increases with cutting force due to the occurrence of a new factor called friction. The friction factor, which is produced between the component and cutting edge of the tool, due to the increasing amount of feed rate, increases the cutting force $[35,42]$. While further analyzing the effect of SiCp/Al MMC materials on the cutting forces, it is mainly found in the literature that the cutting forces primarily tend to be affected by the type of matrix materials rather than reinforcement. It is mainly found that the volume, interface bond strength and reinforcement type heavily influence the cutting edge, which ultimately fluctuates the cutting forces $[43,44]$.

\subsubsection{Quantitative Evaluation Using ANOVA}

As presented before, the influence of each single factor at individual response is determined by utilizing analysis of variance (ANOVA). The ANOVA functioned, based on parameters, which are $F$ statistics, value of $P$ and sum of squares (SS). The $F$ statistics is achieved by dividing the MS of the factor through MS of error. The value of $P$ signifies the statistical worth, which needs to signify the level of 0.05 at confidence interval 95\%, if the value of $P$ is lower from 0.05 the factor used is a significant factor $[14,45]$.

Tables 3-5 display the ANOVA for cutting force responses $F_{x}, F_{y}$, and $F_{z}$ for the turning process of $\mathrm{SiCp} / \mathrm{Al}$. Research on the basis of the above-mentioned variables divulges that the increasing variation in 
cutting force is the result of increasing depth of cut trailed by cutting speed and feed rate. In the same way, the $F$ statistics gives the similar information, the proportional significance of the depth of cut is greater, subsequently trailed by the other factors such as cutting speed and feed rate. The value of $P$ is also asserting the significance of cutting speed and feed rate [46].

Table 3. Analysis of variance of response surface regression: $F_{x}$ versus $v_{c}, f, a_{p}$.

\begin{tabular}{cccccc}
\hline Source & DF & Adj SS & Adj MS & F-Value & P-Value \\
\hline Model & 9 & 355,838 & 39,538 & 95.08 & 0.000 \\
Linear & 3 & 121,663 & 40,554 & 97.53 & 0.000 \\
$v_{c}$ & 1 & 2104 & 2104 & 5.06 & 0.065 \\
$f$ & 1 & 684 & 684 & 1.65 & 0.247 \\
$a_{p}$ & 1 & 119,441 & 119,441 & 287.24 & 0.000 \\
Square & 3 & 1674 & 558 & 1.34 & 0.346 \\
$v_{c} \times v_{c}$ & 1 & 21 & 21 & 0.05 & 0.831 \\
$f \times f$ & 1 & 5 & 5 & 0.01 & 0.913 \\
$a_{p} \times a_{p}$ & 1 & 1648 & 1648 & 3.96 & 0.094 \\
$2-$ Way Interaction & 3 & 6982 & 2327 & 5.60 & 0.036 \\
$v_{c} \times a_{p}$ & 1 & 153 & 153 & 0.37 & 0.566 \\
$v_{c} \times a_{p}$ & 1 & 5114 & 5114 & 12.30 & 0.013 \\
$f \times a_{p}$ & 1 & 344 & 344 & 0.83 & 0.398 \\
Error & 6 & 2495 & 416 & - & - \\
Total & 15 & 358,333 & - & - & - \\
\hline
\end{tabular}

Table 4. Analysis of variance response surface regression: $F_{y}$ versus $v_{\mathcal{c}}, f, a_{p}$.

\begin{tabular}{cccccc}
\hline Source & DF & Adj SS & Adj MS & F-Value & $\boldsymbol{P}$-Value \\
\hline Model & 9 & $50,355.7$ & 5595.1 & 8.29 & 0.009 \\
Linear & 3 & $11,551.9$ & 3850.6 & 5.71 & 0.034 \\
$v_{c}$ & 1 & 1379.3 & 1379.3 & 2.04 & 0.203 \\
$f$ & 1 & 360.2 & 360.2 & 0.53 & 0.493 \\
$a_{p}$ & 1 & $10,131.1$ & $10,131.1$ & 15.01 & 0.008 \\
Square & 3 & 1016.6 & 338.9 & 0.50 & 0.695 \\
$v_{c} \times v_{c}$ & 1 & 77.9 & 77.9 & 0.12 & 0.746 \\
$f \times f$ & 1 & 73.4 & 73.4 & 0.11 & 0.753 \\
$a_{p} \times a_{p}$ & 1 & 865.4 & 865.4 & 1.28 & 0.301 \\
$2-$ Way Interaction & 3 & 805.6 & 268.5 & 0.40 & 0.760 \\
$v_{c} \times a_{p}$ & 1 & 665.9 & 665.9 & 0.99 & 0.359 \\
$v_{c} \times a_{p}$ & 1 & 30.5 & 30.5 & 0.05 & 0.839 \\
$f \times a_{p}$ & 1 & 70.0 & 70.0 & 0.10 & 0.758 \\
Error & 6 & 4048.8 & 674.8 & - & - \\
Total & 15 & $54,404.5$ & - & - & - \\
\hline
\end{tabular}

The different plots were generated to analyze and understand the influence of cutting parameters on the machining behavior of SiCp/Al. This study uses the contour and main effect plots to measure and analyze the responses of cutting force such $F_{x}, F_{y}$, and $F_{z}$. The predicted regression model of the cutting forces is found most appropriate, the equation of cutting forces are given in Equations (3)-(5).

$$
\begin{gathered}
F_{x}=50.8-6.30 v_{c}+3317 f+110.7 a_{p}-0.029 v_{c} \times v_{c}-23,275 f \times f+57.8 a_{p} \times a_{p}+136 v_{c} \times f+ \\
9.13 v_{c} \times a_{p}-2977 f \times a_{p}
\end{gathered}
$$




$$
\begin{gathered}
F_{y}=104+6.19 v_{c}+1845 f+146 a_{p}+0.056 v_{c} \times v_{c}+85,650 f \times f-41.9 a_{p} \times a_{p}-284 v_{c} \times f- \\
0.71 v_{c} \times a_{p}+1342 f \times a_{p} \\
F_{z}=56.1-4.58 v_{c}+4334 f+79.0 a_{p}-0.0515 v_{c} \times v_{c}-144,000 f \times f+18.0 a_{p} \times a_{p}+224 v_{c} \times f+ \\
3.30 v_{c} \times a_{p}+81 f \times a_{p}
\end{gathered}
$$

The mathematical model accuracy is more than $95 \%$ confidence level for all responses of the cutting force in ANOVA. Therefore, the model is most suitable for the prediction of responses [45]. The ANOVA tables for the three different responses of cutting force such $F_{x}, F_{y}$, and $F_{z}$ have been given in Tables 3-5 respectively. The value of $R$ square and $R$ square (adj) for $F_{x}$ are obtained as $R$-sq $99.3 \%$ and $R$-sq (adj) $98.26 \%$; for $F_{y}$ they are obtained as $R$-sq $92.56 \%$ and $R$-sq (adj) $81.39 \%$; and for $F_{z}$ they are are obtained such as $R$-sq $99.2 \%$ and $R$-sq (adj) $97.99 \%$. The values of all the co-efficient of determination of $R$-sq and $R$-sq (adj) are very close to the value of 1 that fulfill the accuracy of the developed mathematical model.

$R$ square quantity is known as a co-efficient of determination, which is utilized to observe the adequacy of the models. The more the value of $R$ square near to 1 gives a higher fitting of the mathematical model with the obtained data. $R$ square value indicates the acceptability of the developed model $[14,47]$.

Table 5. Analysis of variance of response surface regression: $F_{z}$ versus $v_{\mathcal{c}}, f, a_{p}$.

\begin{tabular}{cccccc}
\hline Source & DF & Adj SS & Adj MS & F-Value & $\boldsymbol{P}$-Value \\
\hline Model & 9 & $89,080.0$ & 9897.8 & 82.20 & 0.000 \\
Linear & 3 & $36,376.0$ & $12,125.3$ & 100.69 & 0.000 \\
$v_{c}$ & 1 & 66.9 & 66.9 & 0.56 & 0.484 \\
$f$ & 1 & 1283.5 & 1283.5 & 10.66 & 0.017 \\
$a_{p}$ & 1 & $35,071.4$ & $35,071.4$ & 291.25 & 0.000 \\
Square & 3 & 433.0 & 144.3 & 1.20 & 0.387 \\
$v_{c} \times v_{c}$ & 1 & 66.3 & 66.3 & 0.55 & 0.486 \\
$f \times f$ & 1 & 207.4 & 207.4 & 1.72 & 0.237 \\
$a_{p} \times a_{p}$ & 1 & 159.4 & 159.4 & 1.32 & 0.294 \\
$2-$ Way Interaction & 3 & 1137.2 & 379.1 & 3.15 & 0.108 \\
$v_{c} \times f$ & 1 & 416.3 & 416.3 & 3.46 & 0.112 \\
$v_{c} \times a_{p}$ & 1 & 665.9 & 665.9 & 5.53 & 0.057 \\
$f \times a_{p}$ & 1 & 0.3 & 0.3 & 0.00 & 0.965 \\
Error & 6 & 722.5 & 120.4 & - & - \\
Total & 15 & $89,802.5$ & - & - & - \\
\hline
\end{tabular}

\subsubsection{Individual Effect Evaluation Using Main Effects Plots}

The main effect diagram showing the influences of the input factors to turning of SiCp/Al $45 \mathrm{wt} \%$ shows the cutting forces of $F_{x}, F_{y}$, and $F_{z}$ in Figures 2-4, respectively. Different parameters were chosen to measure the effect on the machining process such as cutting speed, feed rate and depth of cut. In the main effect plot, the horizontal line of the input parameters has little or no effect on the output response, while the vertical line has a significant effect on the response. The $F_{x}$ chart shows that the depth of cut has a greater effect on the cutting force, and the feed rate has a smaller or no effect on the cutting force. Other researchers have also noticed that the cutting force increases with increasing depth of cut, followed by the feed rate [14,36]. Cutting force main effect plot for $F_{y}$ shows that there is a little effect of cutting speed and feed rate however the depth of cut is significantly affecting the cutting force. In the case of $F_{z}$ cutting force, it follows the feed rate to depth of cut, which affects the cutting force to follow the cutting speed to a certain extent. 


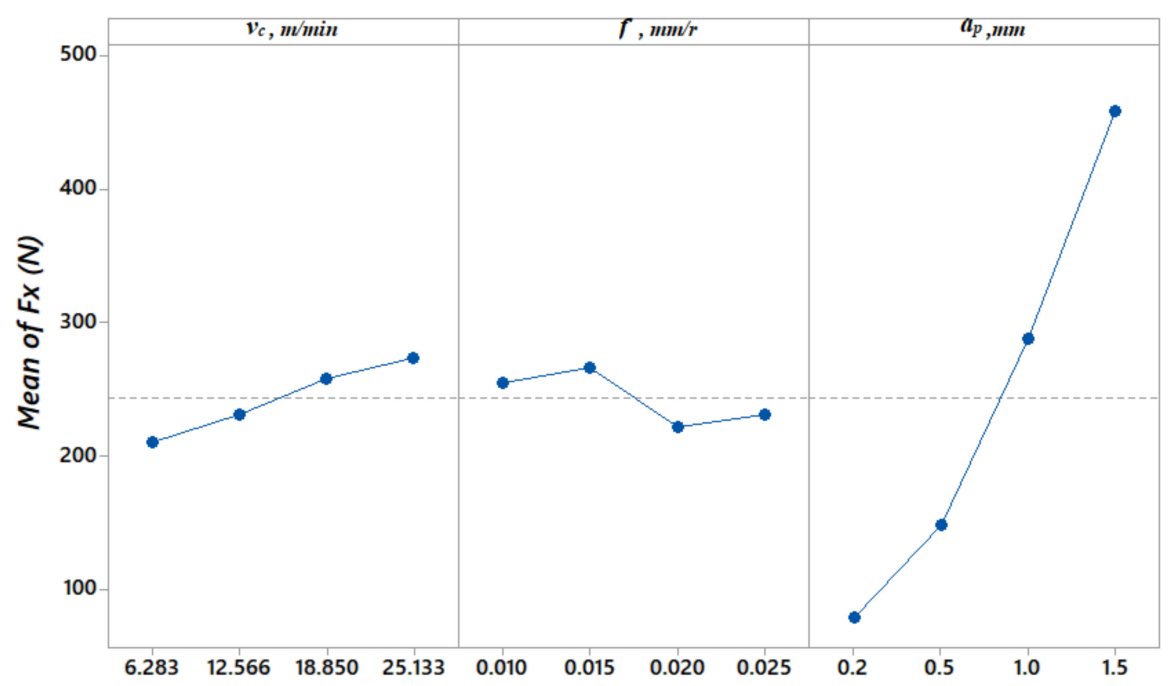

Figure 2. Main effect plots for $F_{x}$ cutting force.

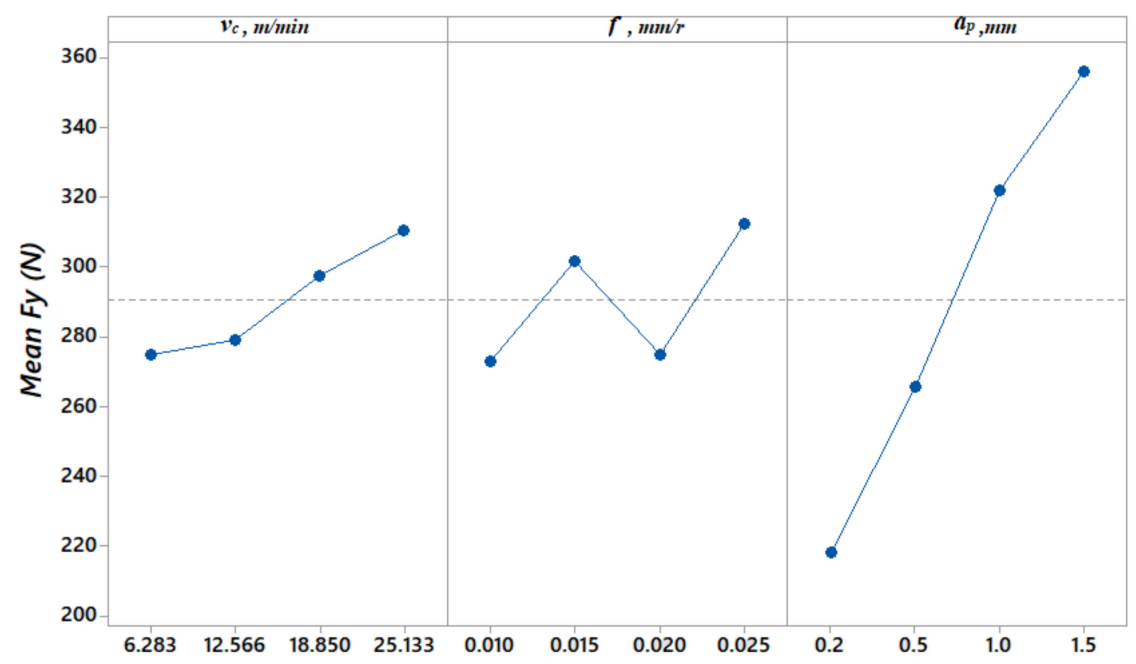

Figure 3. Main effect plots for $F_{y}$ cutting force.

\subsubsection{Interactive Effect Evaluation Using Contour Plots}

While turning of multiphase composite materials like $\mathrm{SiCp} / \mathrm{Al}$ with $45 \mathrm{wt} \%$ through carbide cutting tool wedge, it experienced abrasion and force variability because of the contact with brittle particles in the materials. Based on the present model of RSM which are shown in regression Equation (3), regression Equation (4), and regression Equation (5), these are made based on experimental annotations to measure the influence of nominated parameters on the cutting force. The contour plots were formed to shape the possible influence of different selected parameters. In case of depth of cut as the depth of cut rises followed by feed rate there is an accelerated increment of the cutting force, the trend is depicted in Figure 5a. However, similarly shown in [15], for the turning process of SiCp/Al solely observed, the increasing phenomena of cutting force with increasing depth of cut followed by feed rate, while cutting force reduces with an increase in cutting speed. Figure $5 c$ divulge the clear statistics that as the cutting speed increases and the depth of cut decreases, the cutting force gives declining trending. It is due to the fact that higher amount of cutting speed create high temperature at the cutting zone; because of increasing temperature it causes thermal softening due to that it creates ease in chip formation, therefore, cutting force 
reduces $[22,33]$. The increasing feed rate with a combination of increasing depth of cut at moderate cutting speed produces an increasing impact on movement of $F_{y}$ cutting force as compared to $F_{x}$, and $F_{z}$ cutting force as shown in Figure $6 \mathrm{~b}$. With the maximum value of $1.5 \mathrm{~mm}$ depth of cut as holding value in all directions of cutting force $F_{x}, F_{y}, F_{z}$, the contour plots show the same increasing phenomena as shown in Figures $5 b, 6 c$ and $7 c$, respectively. However, in case of holding the cutting speed to reveal the impact of cutting speed with increasing feed rate and depth of cut, it shows reducing trend in cutting force with higher cutting speed and lower depth of cut. Followed by feed rate in $F_{x}$, and $F_{y}$, the direction of cutting force in $F_{z}$ there is slight addition with increasing feed rate as shown in Figures 5a, 6b and 7a. This kind of phenomenon also reported by Subramanian et al. [16] that the more increments in feed rate alone increase the cutting force due to increasing the contact area between workpiece and cutting tool.

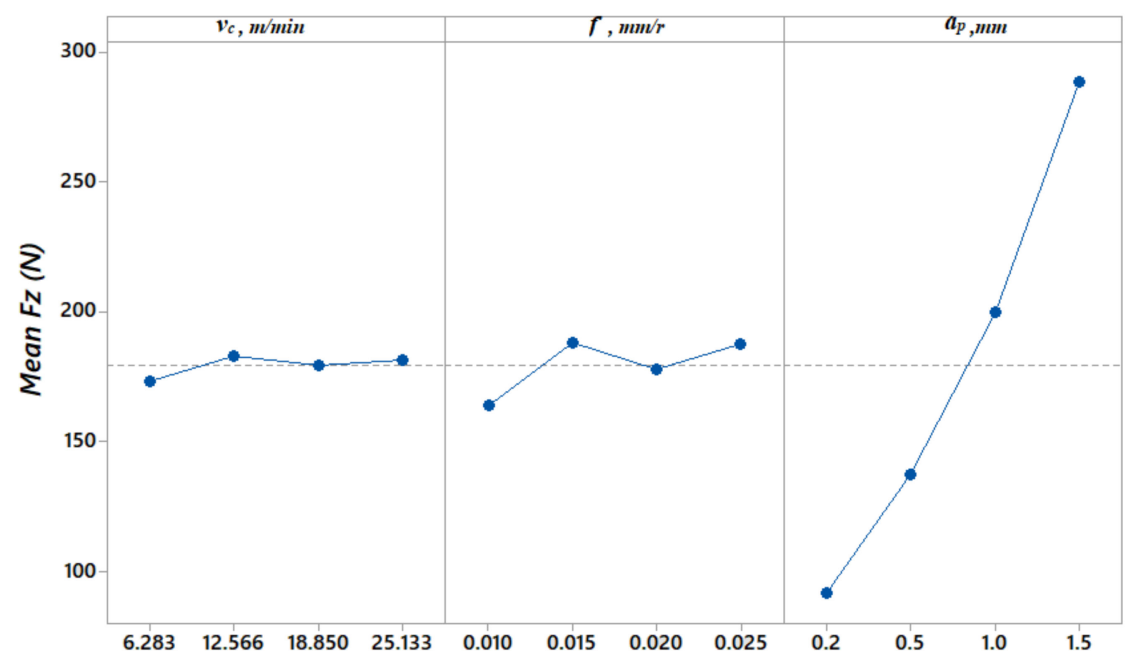

Figure 4. Main effect plots for $F_{z}$ cutting force.

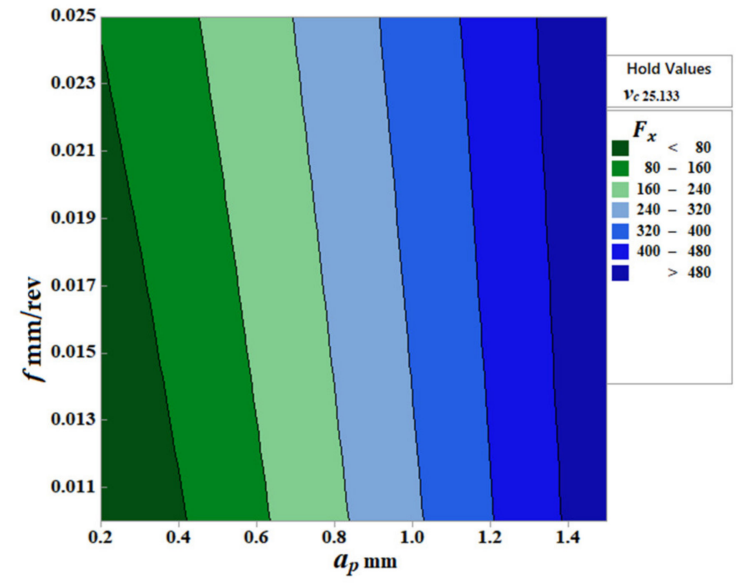

(a) Cutting force $F_{x}$ vs $f$, and $a_{p}$

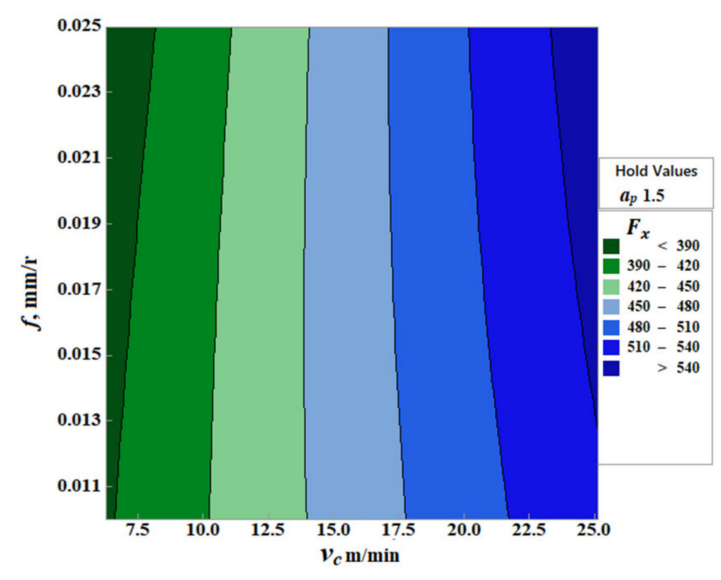

(b) Cutting force $F_{x}$ vs $f$, and $v_{c}$

Figure 5. Cont. 


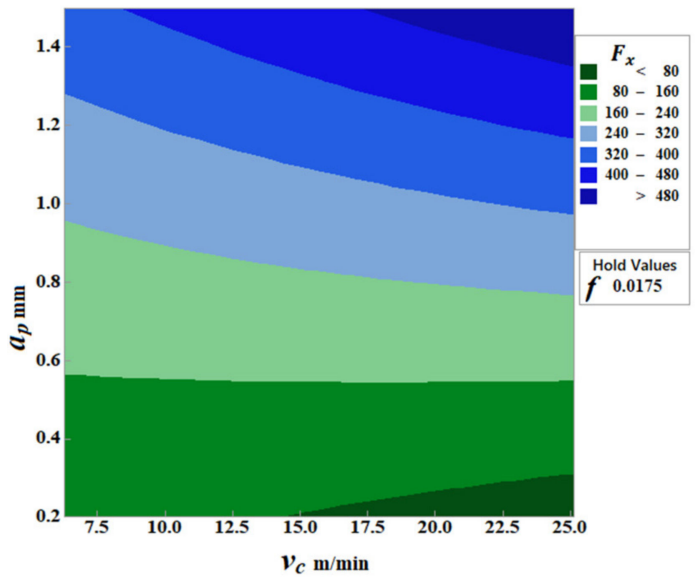

(c) Cutting force $F_{x} \mathrm{vs} a_{p}$ and $v_{c}$

Figure 5. (a-c) Cutting force $F_{x}$ vs. $v_{\mathcal{c}}, f, a_{p}$.

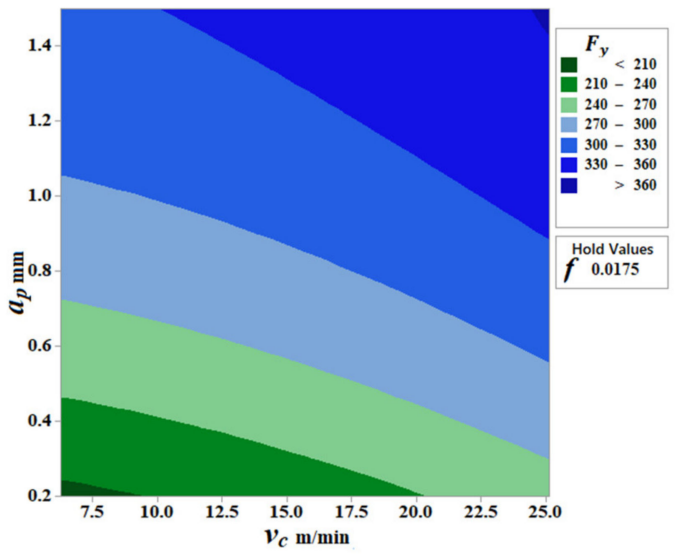

(a) Cutting force $F_{y}$ vs $a_{p}$ and $v_{c}$

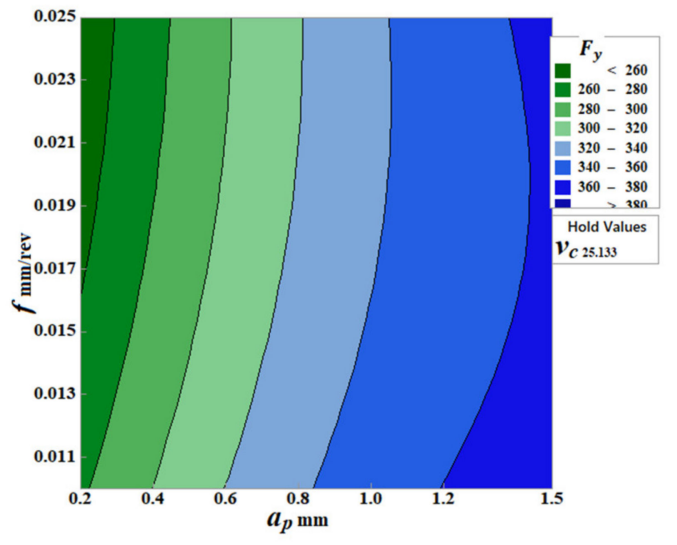

(b) Cutting force $F_{y}$ vs $f$, and $a_{p}$

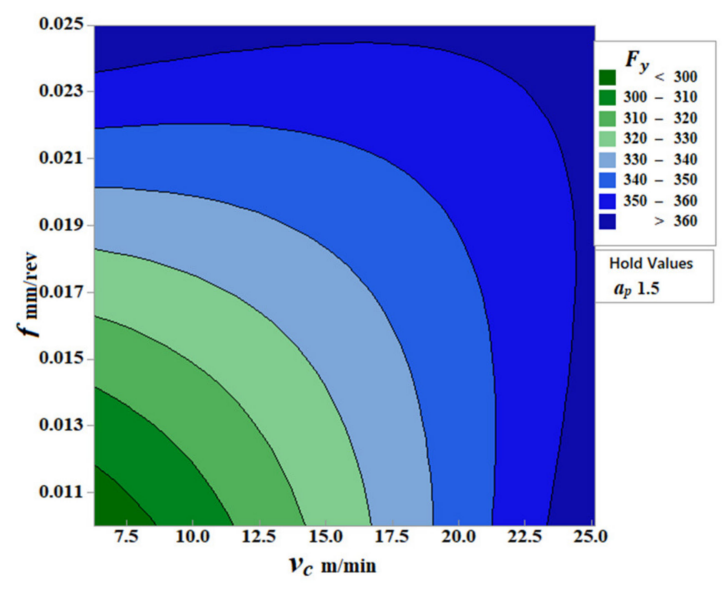

(c) Cutting force $F_{y}$ vs $f$, and $v_{c}$

Figure 6. (a-c) Cutting force $F_{y}$ vs. $v_{c}, f, a_{p}$. 


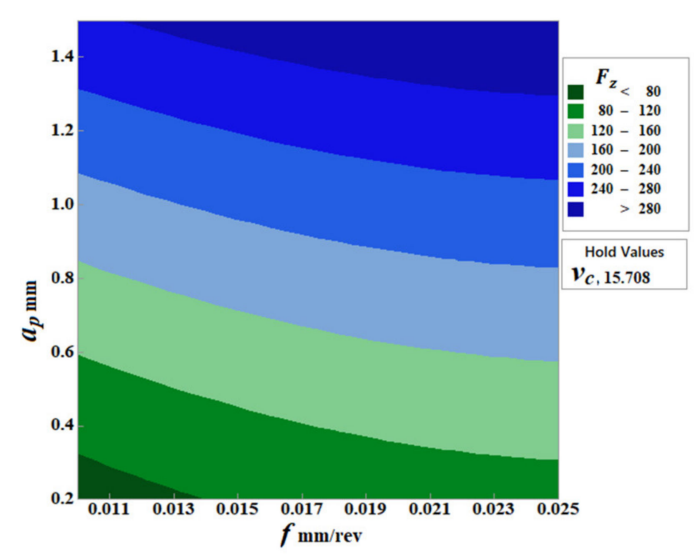

(a) Cutting force $F_{z}$ vs $a_{p}$ and $f$

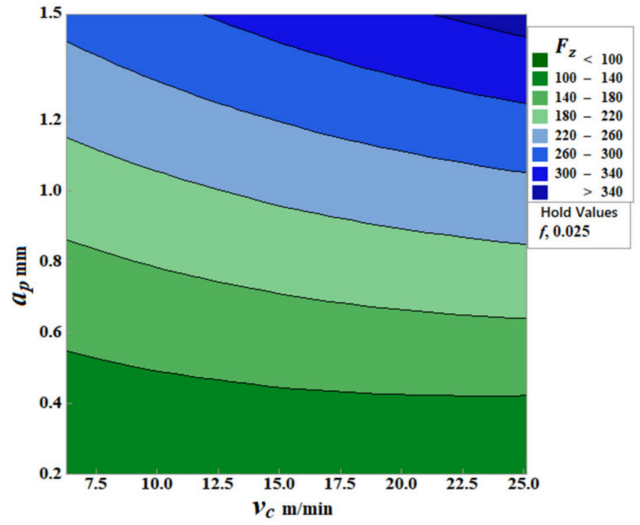

(b) Cutting force $F_{z}$ vs $a_{p}$ and $v_{c}$

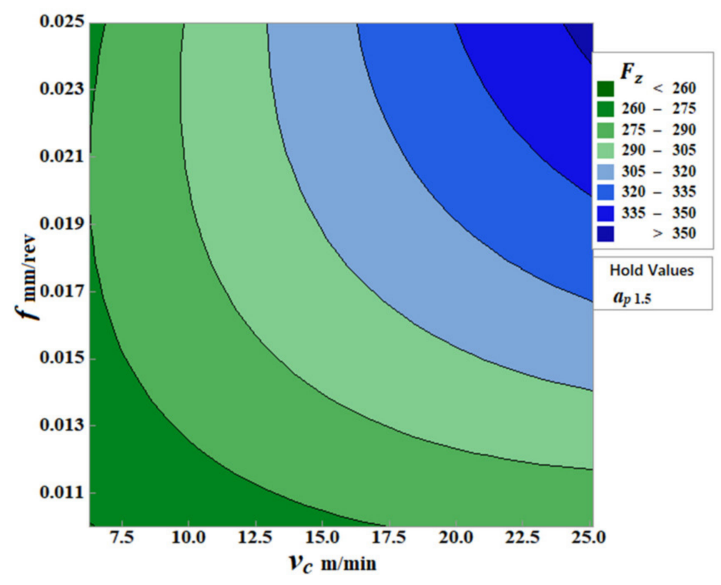

(c) Cutting force $F_{z}$ vs $f$, and $v_{c}$

Figure 7. (a-c) Cutting force $F_{z}$ vs. $v_{c}, f, a_{p}$.

\subsection{Integrity of Models Using Residual Analysis}

The residual plot is one of the important tools to evaluate the integrity of the developed model and plays a key role [30]. Figures 8-10 show the residual plot of the cutting forces $F_{x}, F_{y}$, and $F_{z}$ respectively. There are four plots of the cutting force's arrival response, i.e., normal probability plots, residual and fit plots, residual histograms, and residual and observation sequence plots. In analyzing all four different plots seen here, in the normal probability plot, the data points reasonably approach the straight line; therefore, the normality assumption still applies [48]. Residual plots and fitted plots indicate that the data points are randomly distributed; therefore, the assumption of constant variance is accurate [49]. On the other hand, there is some distortion on the left side of the histogram. Finally, in the residual sequence chart, the first segment showed an upward trend and then fluctuated significantly. Figure 6 shows a residual curve of the cutting force $F_{y}$. The residuals of this method are normally distributed and are suitable for analysis of ordinary variance, but at the initial stage and the later stage, the distortion at the left end is small, and the correlation coefficient increases or decreases. Figure 7 shows a residual graph of the cutting force $F_{z}$. Here, the residuals are normally distributed, all three sets of data are visible, the distortion is not visible, and the trend of increase and decrease is obvious. 

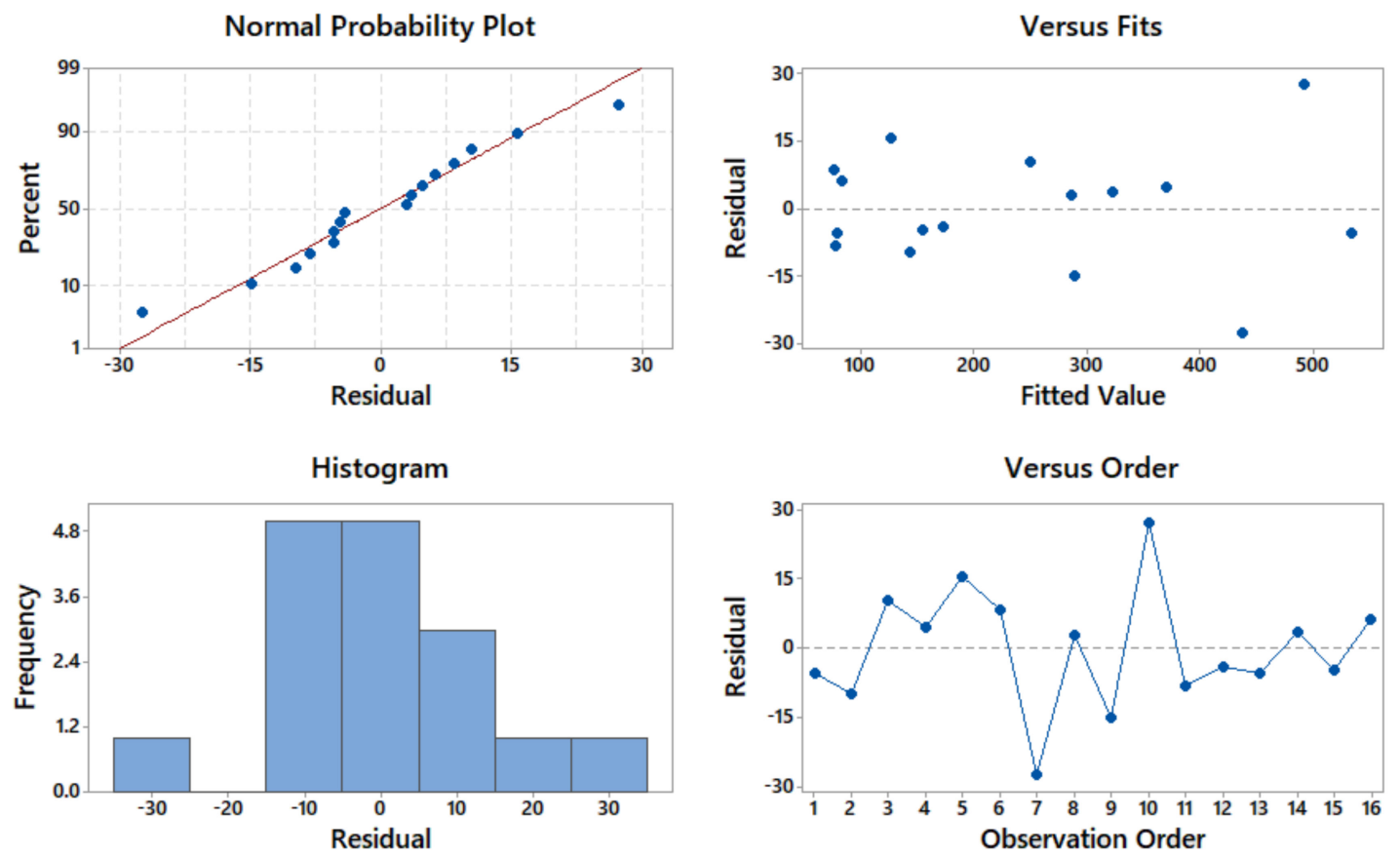

Figure 8. Residual plot of the cutting force $F_{x}$.
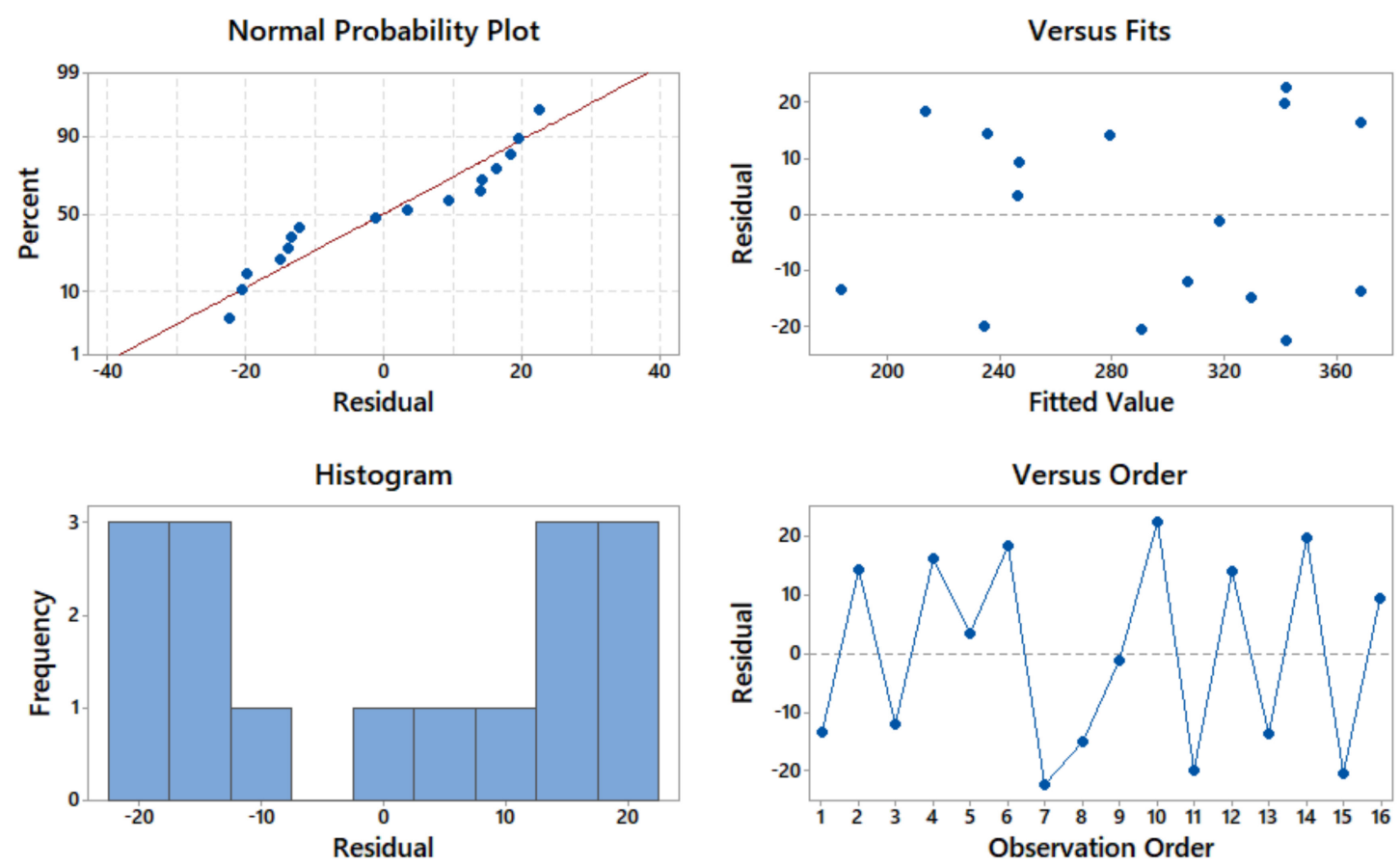

Figure 9. Residual plot of the cutting force $F_{y}$. 

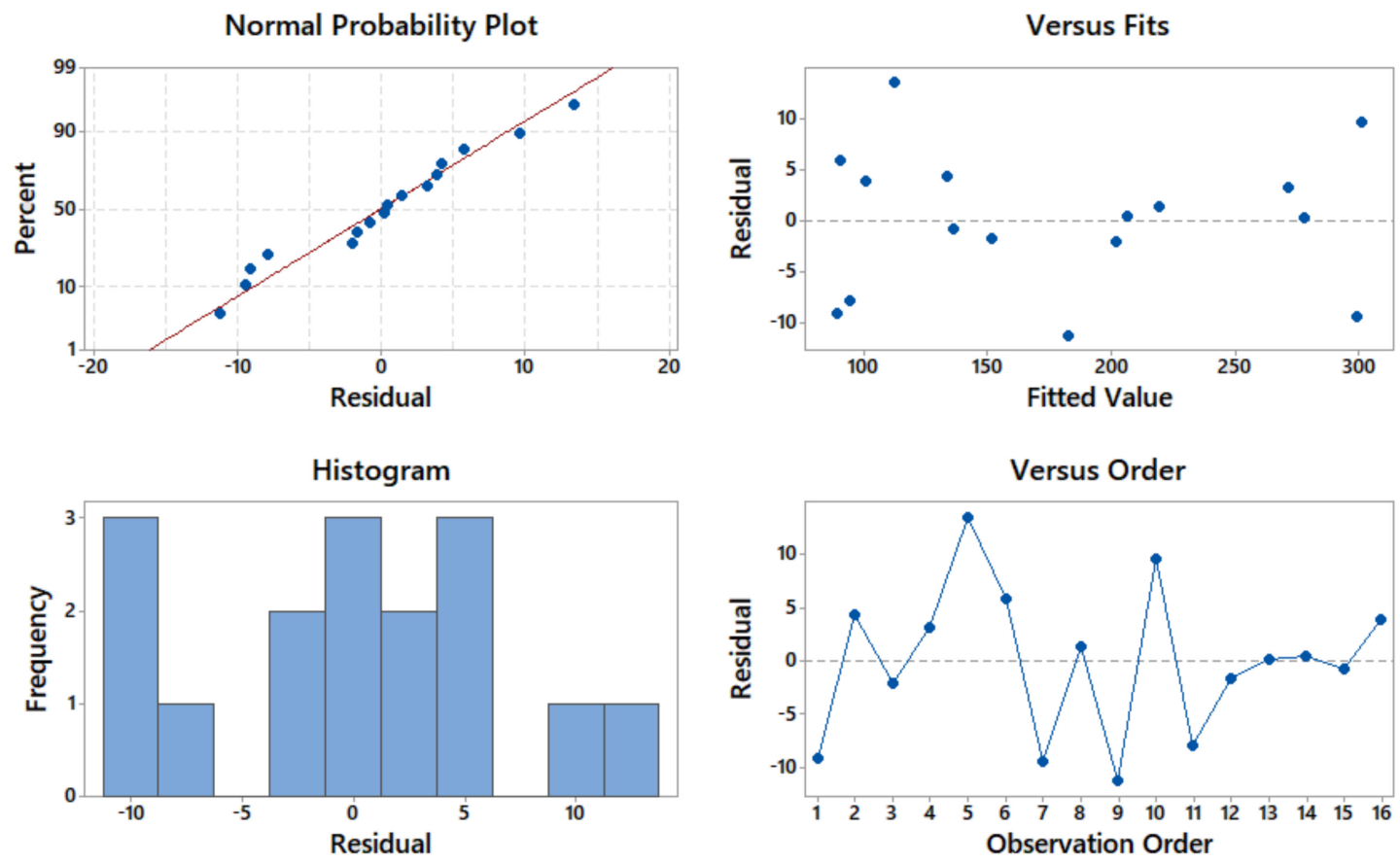

Figure 10. Residual plot of the cutting force $F_{z}$.

\subsection{Optimization of Cutting Forces Using Desirability Function}

The cutting force trend in the turning process of $\mathrm{SiCp} / \mathrm{Al}$ material has a significant theoretical and practical consequence. The cutting forces were observed as major impacting factors in the machining process. On a different combination of cutting parameters and weight percentage of $\mathrm{SiC}$ particles in $\mathrm{SiCp} / \mathrm{Al}$ material, the cutting forces significance was found accordingly. Evidence shows that the cutting force varies with the change in cutting parameters. The type, hardness and content, shape, size, and distribution of the reinforcement in $\mathrm{SiCp} / \mathrm{Al}$ influence the cutting force. In the turning process, due to the extrusion, shearing, and friction between the tool and the workpiece, the cutting layer of the workpiece undergoes strong elastic and plastic deformation. The root cause of these deformations is the effect of cutting forces. Hence, the cutting force is one of the most basic physical phenomena in material cutting $[40,41,50]$.

Cutting force optimization plot for $F_{x}, F_{y}$, and $F_{z} \mathrm{SiCp} / \mathrm{Al} 45 \mathrm{wt} \%$ has been given in Figure 11 . The purpose is to minimize the cutting force. For $F_{x}, F_{y}$, and $F_{z}$ the setting of values for the optimization plot is given as the lower, and the target values are 69.01, 170.01 and $79.98 \mathrm{~N}$ respetively and upper values are $529.98,385.11$ and $311.05 \mathrm{~N}$ for $F_{x}, F_{y}$, and $F_{z}$ respectively. The optimization plot for minimization of cutting force suggests that the cutting parameters are cutting speed $\left(v_{c}\right)$ of $6.283 \mathrm{~m} / \mathrm{min}$, feed rate $(f)$ of $0.01 \mathrm{~mm} / \mathrm{rev}$ and depth of cut $\left(a_{p}\right)$ of $0.2 \mathrm{~mm}$. The value of desirability $(d)$ of optimization is noted at 0.9576. The projected response for the cutting force $F_{x}, F_{y}$, and $F_{z} \mathrm{SiCp} / \mathrm{Al} 45 \mathrm{wt} \%$ are $79.5160,183.3829$ and $89.1095 \mathrm{~N}$ respectively. Similiarly, the cutting force maximization was ploted to find the parameters which increases the cutting force with similar settings, such as lower value targeted and the upper value in Figure 12. However, in Figure 12 targeted value and uper value are similar. The projected response for identifying the maximized cutting force $F_{x}, F_{y}$, and $F_{z} \mathrm{SiCp} / \mathrm{Al} 45 \mathrm{wt} \%$ are 557.0966, 364.9312 and 89.1095 $\mathrm{N}$ respectively. The desirability is 0.9584 . The regression equation used for response optimizer plots for $F_{x}$, $F_{y}$, and $F_{z} \mathrm{SiCp} / \mathrm{Al} 45 \mathrm{wt} \%$ is given in Equations (6)-(8). 


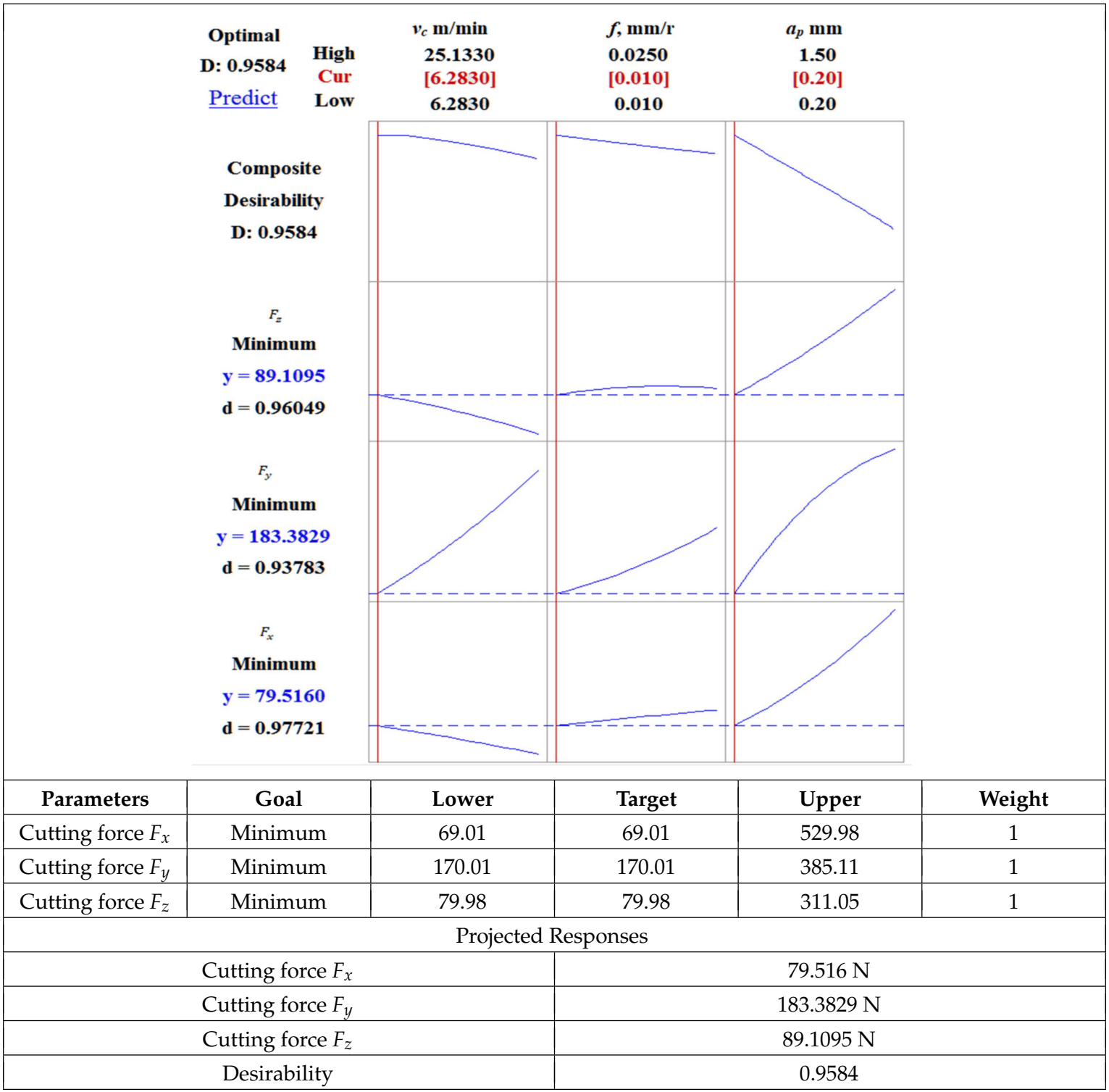

Figure 11. Optimization Plot for Minimum Cutting Force of $F_{x}, F_{y}, F_{z} \mathrm{SiCp} / \mathrm{Al}$.

Regression Equation for $F_{x}, F_{y}$, and $F_{z} \operatorname{SiCp} / \mathrm{Al} 45 \%$ wt.

$$
\begin{aligned}
& F_{x}=v_{c}+f+a_{p}-v_{c} \times v_{c}-f \times f+a_{p} \times a_{p}+v_{c} \times f+v_{c} \times a_{p}-f \times a_{p} \\
& F_{y}=v_{c}+f+a_{p}+v_{c} \times v_{c}+f \times f-a_{p} \times a_{p}-v_{c} \times f-v_{c} \times a_{p}+f \times a_{p} \\
& F_{z}=v_{c}+f+a_{p}-v_{c} \times v_{c}-f \times f+a_{p} \times a_{p}+v_{c} \times f+v_{c} \times a_{p}+f \times a_{p}
\end{aligned}
$$

A comparison of the experimental cutting force values Table 2 and predicted cutting force values is shown in Table 6 . This is not the validation of the model but a table to show the differences found for the cutting force values. The RSM predicted model was compared with the experimental values and found in good agreement as shown in Figure 13. The error (difference) percentages between model predicted and experimental values are compared in Figure 14-majority of the error percentages are under 10\% 
except for the few values which are up to $16 \%$. Few error percentages are above $10 \%$-it can be due to some tool's measurement calculation error and machine vibration during cutting process of $\mathrm{SiCp} / \mathrm{Al}$ composite materials.

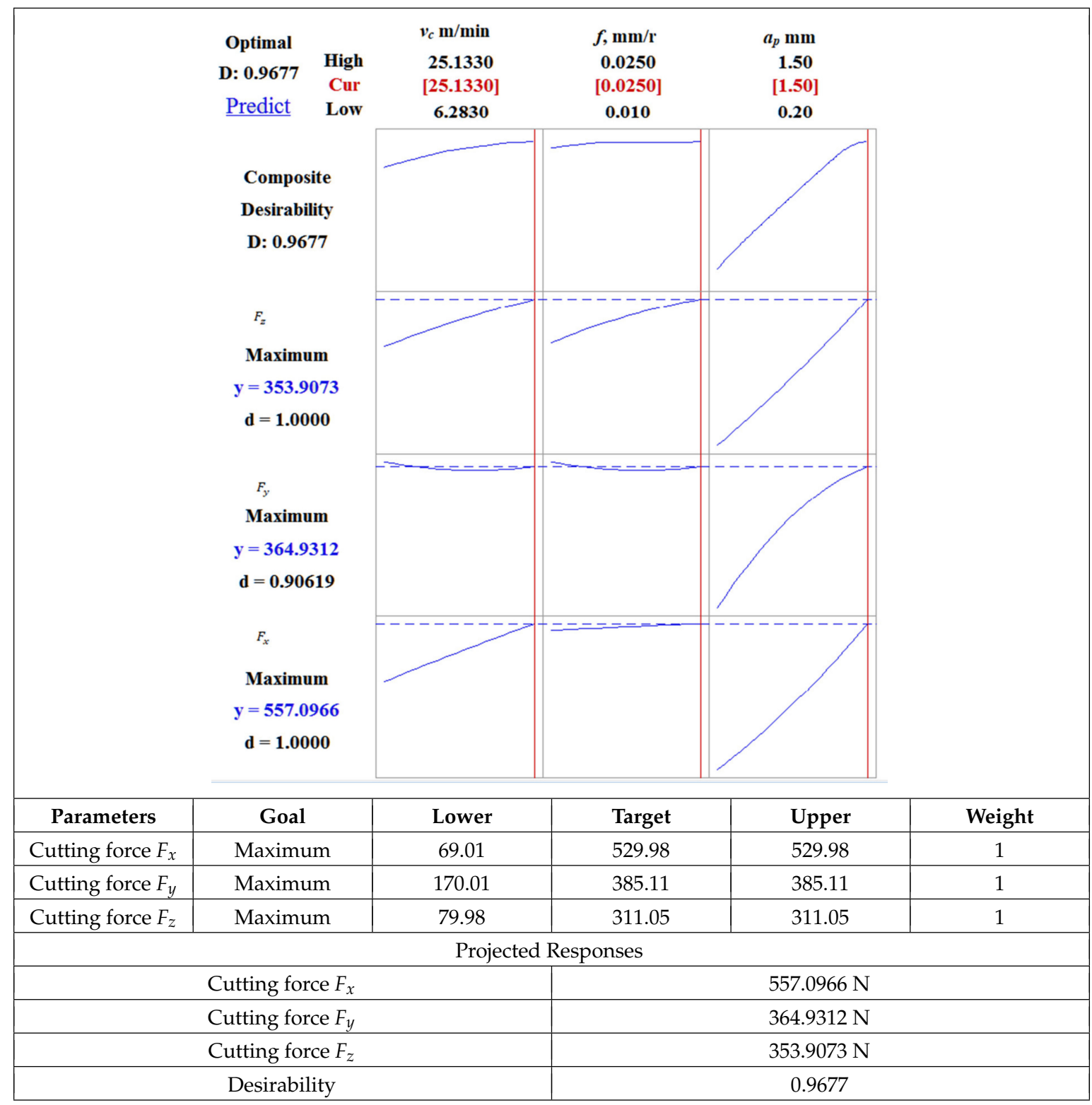

Figure 12. Optimization Plot for Maximum Cutting Force of $F_{x}, F_{y}, F_{z} \mathrm{SiCp} / \mathrm{Al}$. 
Table 6. The machining parameters and comparison of experimental cutting force $F_{x}, F_{y}, F_{z}$ vs. measured cutting force $F_{x}, F_{y}, F_{z}$.

\begin{tabular}{|c|c|c|c|c|c|c|c|c|c|}
\hline \multirow{2}{*}{ S: No } & \multicolumn{3}{|c|}{$F_{x}$} & \multicolumn{3}{|c|}{$F_{y}$} & \multicolumn{3}{|c|}{$F_{z}$} \\
\hline & Exp. Force (N) & Pred. Force (N) & Error \% & Exp. Force (N) & Pred. Force (N) & Error \% & Exp. Force (N) & Pred. Force (N) & Error \% \\
\hline 1 & 74.13 & 79.39 & 7.09 & 170.01 & 180.91 & 6.41 & 79.98 & 88.41 & 10.5 \\
\hline 2 & 134.01 & 143.19 & 6.85 & 249.9 & 235.64 & 5.7 & 138.23 & 132.12 & 4.42 \\
\hline 3 & 261.09 & 250.51 & 4.05 & 295.03 & 307.05 & 4.07 & 199.81 & 183.87 & 7.97 \\
\hline 4 & 375.29 & 370.3 & 1.32 & 385.11 & 368.5 & 4.31 & 275.12 & 231.42 & 16 \\
\hline 5 & 143.11 & 127.26 & 11.06 & 250.07 & 246.72 & 1.32 & 126.06 & 108.14 & 14.2 \\
\hline 6 & 84.33 & 71.6 & 15.09 & 231.96 & 213.8 & 7.82 & 96.11 & 89.58 & 6.79 \\
\hline 7 & 409.98 & 445.4 & 8.53 & 319.99 & 338.24 & 5.7 & 289.88 & 258.92 & 10.6 \\
\hline 8 & 290.11 & 286.26 & 1.32 & 315.06 & 329.83 & 4.68 & 221.02 & 201.62 & 8.77 \\
\hline 9 & 274.42 & 289 & 5.31 & 317.1 & 318.19 & 0.34 & 171.3 & 182.64 & 6.62 \\
\hline 10 & 519.8 & 479.16 & 7.81 & 364.89 & 342.06 & 6.25 & 311.05 & 307.19 & 1.24 \\
\hline 11 & 69.01 & 77 & 11.57 & 214.87 & 234.88 & 9.3 & 86.42 & 100.82 & 15.7 \\
\hline 12 & 169.04 & 172.49 & 2.04 & 293.15 & 268.2 & 8.51 & 149.79 & 160.91 & 7.4 \\
\hline 13 & 529.98 & 534.27 & 0.8 & 355.23 & 368 & 3.59 & 278.31 & 277.87 & 0.15 \\
\hline 14 & 327.16 & 306.6 & 6.28 & 361.01 & 341.21 & 5.48 & 207.04 & 206.67 & 0.17 \\
\hline 15 & 149.97 & 153.94 & 2.64 & 269.96 & 271.92 & 0.72 & 135.61 & 136.41 & 0.58 \\
\hline 16 & 89.96 & 83.43 & 7.25 & 256.14 & 250.17 & 2.33 & 104.97 & 101.06 & 3.7 \\
\hline
\end{tabular}

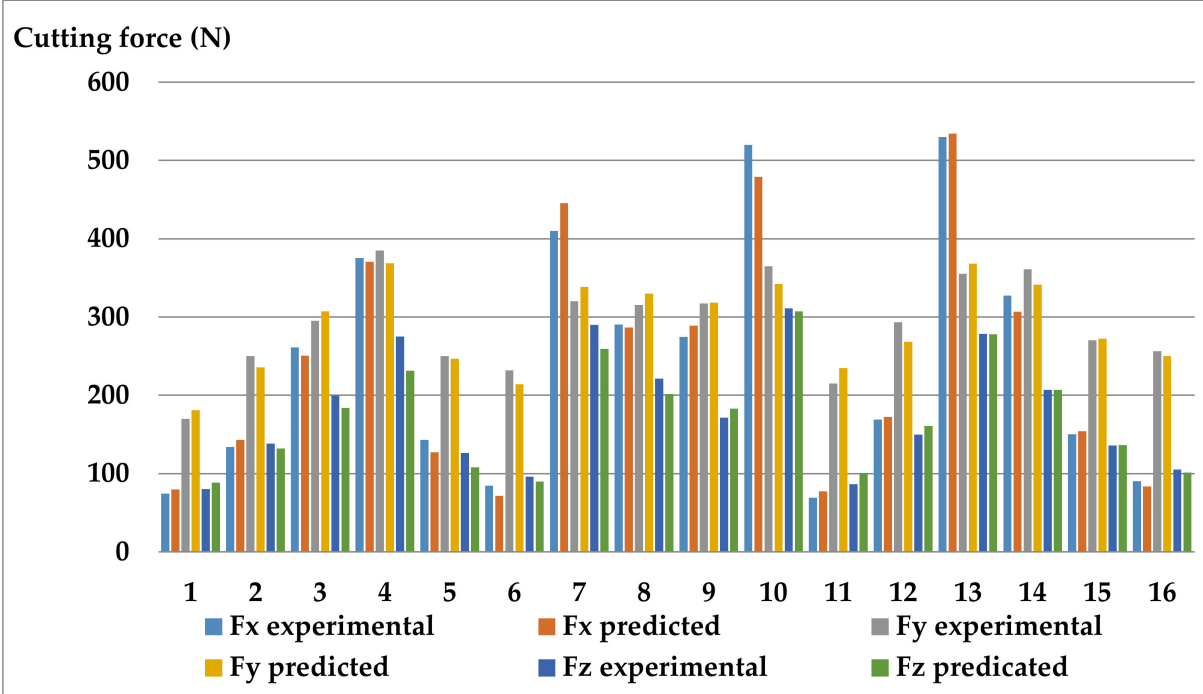

Figure 13. Cutting force comparisons between experimental and RSM predicted values of $F_{x}, F_{y}, F_{z}$.

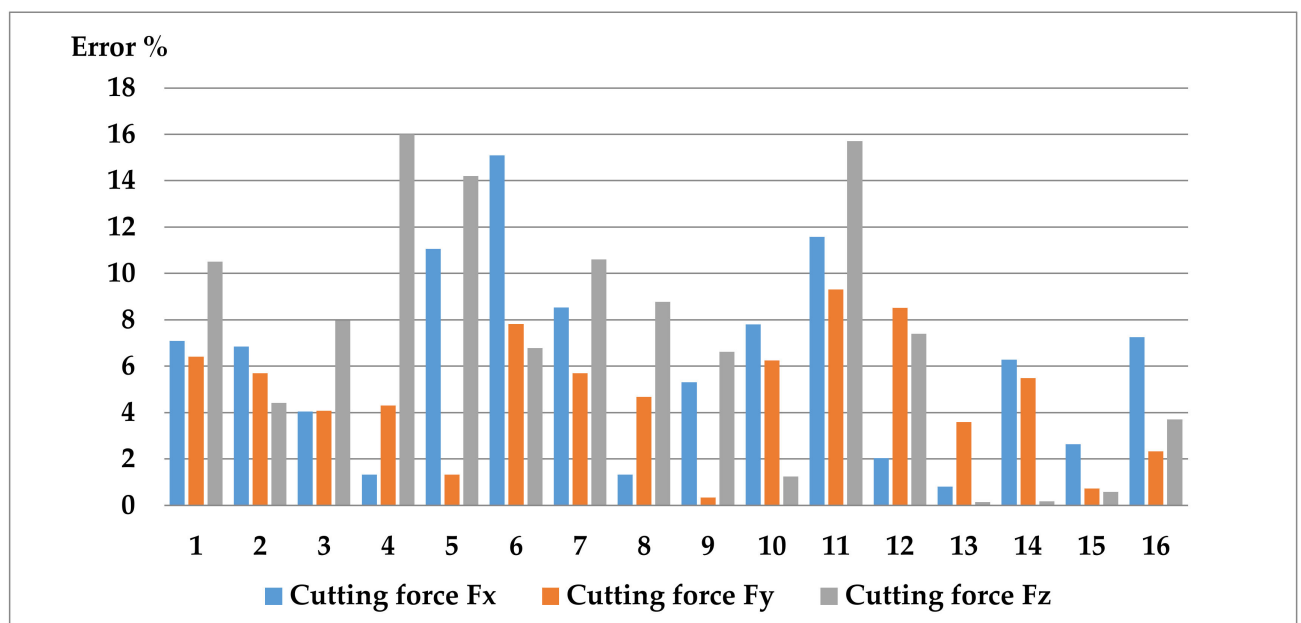

Figure 14. Cutting force error percentage comparison between experimental and RSM predicted values. 


\section{Conclusions}

The experimental research work of this paper investigates the influence of machining parameters on the cutting force in turning process of difficult-to-cut hard material $\mathrm{SiCp} / \mathrm{Al}$ reinforced metal matrix composites. The desirability function has been used for the optimization of the responses. The considered machining parameters were taken as cutting speed, feed rate, and depth of cutting. It was evaluated the impact of SiCp/Al materials on the cutting force. The box-Behnken based mathematical predictive model was developed with RSM for measuring the impact of different input parameters such as cutting speed, feed rate, and depth of cut and $\mathrm{SiC}$ particles on cutting force.

- In machining $\mathrm{SiCp} / \mathrm{Al}$ materials, the machining behavior acted like for the machining of metals/alloys - the depth of cut produced more effect on the cutting force, followed by feed rate. However, the cutting forces (for $F_{x}$ and, $F_{z}$ mostly) show decreasing trend with higher cutting speeds.

- The cutting forces were increasing with the increase in the feed rate which can be accredited to a higher contact area due to increased feed. Also, the content of SiC particles resulted in an increase in the cutting force.

- The increase in cutting speed leads to a decrease in cutting force. It is possible because of the increments in cutting temperature in the shear plane region which leads to the plastic softening of the machined surface. This reduces the shear strength of the SiCp/Al composite material.

- Mathematical models (RSM) showed very competent comparable values of the cutting forces. Here, these equations can be used to predict $\mathrm{SiCp} / \mathrm{Al} 45 \mathrm{wt} \%$ reinforced metal matrix composite cutting forces when turning. RSM generated mathematical models were found accurate and their predicted values were very close to the experimental data points with overall minimal error percentages.

- The composite desirability for optimization, i.e., minimization of cutting forces, which suggest that the optimum cutting parameters are cutting speed $\left(v_{c}\right)$ of $6.283 \mathrm{~m} / \mathrm{min}$, feed rate $(f)$ of $0.01 \mathrm{~mm} / \mathrm{rev}$ and depth of cut $\left(a_{p}\right) 0.2 \mathrm{~mm}$ and the value of $(d)$ desirability of optimization is noted at 0.9576 . The projected response for the cutting force $F_{x}, F_{y}$, and $F_{z}$ and $\mathrm{SiCp} / \mathrm{Al} 45 \mathrm{wt} \%$ are $79.5160(\mathrm{~N}), 183.3829$ $(\mathrm{N})$, and $89.1095(\mathrm{~N})$, respectively.

Author Contributions: R.A.L. wrote the paper and completed the RSM modeling and optimization; J.L. supervised the paper; M.M. revised the manuscript and helped in the structure and design of the manuscript. All authors have read and agreed to the published version of the manuscript.

Funding: This research is not funded by any grant.

Conflicts of Interest: The authors declare no conflict of interest.

\section{References}

1. Laghari, R.A.; Li, J.; Laghari, A.A.; Wang, S. A Review on Application of Soft Computing Techniques in Machining of Particle Reinforcement Metal Matrix Composites. Arch. Comput. Methods Eng. 2019. [CrossRef]

2. Srivastava, A.K.; Dixit, A.R.; Tiwari, S. A review on the intensification of metal matrix composites and its nonconventional machining. IEEE J. Sel. Top. Quantum Electron. 2018, 25, 213-228. [CrossRef]

3. Nicholls, C.J.; Boswell, B.; Davies, I.J.; Islam, M.N. Review of machining metal matrix composites. Int. J. Adv. Manuf. Technol. 2017, 90, 2429-2441. [CrossRef]

4. Hung, N.P.; Zhong, C.H. Cumulative tool wear in machining metal matrix composites. Part I: Modelling. J. Mater. Process. Technol. 1996, 58, 109-113. [CrossRef]

5. Paulo Davim, J. Machining of Metal Matrix Composites; Springer: London, UK, 2012; ISBN 9780857299383.

6. Pugazhenthi, A.; Kanagaraj, G.; Dinaharan, I.; David Raja Selvam, J. Turning characteristics of in situ formed TiB2 ceramic particulate reinforced AA7075 aluminum matrix composites using polycrystalline diamond cutting tool. Measurement 2018, 121, 39-46. [CrossRef] 
7. Davim, J.P. Machining Composite Materials; ISTE-Wiley: London, UK, 2010; ISBN 9781848211704 (hc.)r1848211708 (hc.).

8. Niknam, S.A.; Kamalizadeh, S.; Asgari, A.; Balazinski, M. Turning titanium metal matrix composites (Ti-MMCs) with carbide and CBN inserts. Int. J. Adv. Manuf. Technol. 2018, 97, 253-265. [CrossRef]

9. Li, J.; Laghari, R.A. A review on machining and optimization of particle-reinforced metal matrix composites. Int. J. Adv. Manuf. Technol. 2019, 100, 2929-2943. [CrossRef]

10. Wang, Y.; Liao, W.; Yang, K.; Chen, W.; Liu, T. Investigation on cutting mechanism of SiC p/Al composites in precision turning. Int. J. Adv. Manuf. Technol. 2019, 100, 963-972. [CrossRef]

11. Laghari, R.A.; Li, J.; Xie, Z.; Wang, S.-Q. Modeling and Optimization of Tool Wear and Surface Roughness in Turning of Al/SiCp Using Response Surface Methodology. 3D Res. 2018, 9, 46. [CrossRef]

12. Hung, N.P.; Boey, F.Y.C.; Khor, K.A.; Phua, Y.S.; Lee, H.F. Machinability of aluminum alloys reinforced with silicon carbide particulates. J. Mater. Process. Technol. 1996, 56, 966-977. [CrossRef]

13. Markopoulos, A.P.; Pressas, I.S.; Papantoniou, I.G.; Karkalos, N.E.; Davim, J.P. Machining and Machining Modeling of Metal Matrix Composites-A Review. In Materials Forming, Machining and Tribology; Springer Science and Business Media LLC: Berlin/Heidelberg, Germany, 2015; pp. 99-141.

14. Jeyakumar, S.; Marimuthu, K.; Ramachandran, T. Prediction of cutting force, tool wear and surface roughness of Al6061/SiC composite for end milling operations using RSM. J. Mech. Sci. Technol. 2013, 27, 2813-2822. [CrossRef]

15. Paulo Davim, J.; Monteiro Baptista, A. Relationship between cutting force and PCD cutting tool wear in machining silicon carbide reinforced aluminum. J. Mater. Process. Technol. 2000, 103, 417-423. [CrossRef]

16. Muthusamy Subramanian, A.V.; Nachimuthu, M.D.G.; Cinnasamy, V. Assessment of cutting force and surface roughness in LM6/SiCp using response surface methodology. J. Appl. Res. Technol. 2017, 15, 283-296. [CrossRef]

17. Agarwal, A.; Singh, H.; Kumar, P.; Singh, M. Optimisation of power consumption for CNC turned parts using response surface methodology and Taguchi's technique-A comparative study. J. Mater. Process. Technol. 2008, 200, 373-384. [CrossRef]

18. Kannan, S.; Kishawy, H.A.; Deiab, I. Cutting forces and TEM analysis of the generated surface during machining metal matrix composites. J. Mater. Process. Technol. 2009, 209, 2260-2269. [CrossRef]

19. Tamang, S.K.; Chandrasekaran, M. Modeling and optimization of parameters for minimizing surface roughness and tool wear in turning $\mathrm{Al} / \mathrm{SiCp} \mathrm{MMC}$, using conventional and soft computing techniques. Adv. Prod. Eng. Manag. 2015, 10, 59-72. [CrossRef]

20. Muthukrishnan, N.; Davim, J.P. An investigation of the effect of work piece reinforcing percentage on the machinability of Al-SiC metal matrix composites. J. Mech. Eng 2011, 3, 15-24.

21. Dabade, U.A.; Joshi, S.S.; Balasubramaniam, R.; Bhanuprasad, V.V. Surface finish and integrity of machined surfaces on Al/SiCp composites. J. Mater. Process. Technol. 2007, 192-193, 166-174. [CrossRef]

22. Shin, Y.C.; Dandekar, C. Mechanics and Modeling of Chip Formation in Machining of MMC. In Machining of Metal Matrix Composites; Springer: London, UK, 2012; pp. 1-49.

23. Tansel, I.N.; Arkan, T.T.; Bao, W.Y.; Mahendrakar, N.; Shisler, B.; Smith, D.; McCool, M. Tool wear estimation in micro-machining. Part I: Tool usage-cutting force relationship. Int. J. Mach. Tools Manuf. 2000, 40, 599-608. [CrossRef]

24. Sekhar, R.; Singh, T.P. Mechanisms in turning of metal matrix composites: A review. J. Mater. Res. Technol. 2015, 4, 197-207. [CrossRef]

25. Wan, M.; Li, S.E.; Yuan, H.; Zhang, W.H. Cutting force modelling in machining of fiber-reinforced polymer matrix composites (PMCs): A review. Compos. Part A Appl. Sci. Manuf. 2019, 34-55. [CrossRef]

26. Pérez, H.; Vizán, A.; Hernandez, J.C.; Guzmán, M. Estimation of cutting forces in micromilling through the determination of specific cutting pressures. J. Mater. Process. Technol. 2007, 190, 18-22. [CrossRef]

27. Li, H.Z.; Zeng, H.; Chen, X.Q. An experimental study of tool wear and cutting force variation in the end milling of Inconel 718 with coated carbide inserts. J. Mater. Process. Technol. 2006, 180, 296-304. [CrossRef]

28. Astakhov, V.P. The assessment of cutting tool wear. Int. J. Mach. Tools Manuf. 2004, 44, 637-647. [CrossRef] 
29. Ali Laghari, R.; Li, J.; Laghari, A.A.; Mia, M.; Wang, S.; Aibo, W.; Poonam, K.K. Carbide tool life prediction and modeling in SiCp/Al turning process via artificial neural network approach. IOP Conf. Ser. Mater. Sci. Eng. 2019, 600, 012022. [CrossRef]

30. Mia, M.; Khan, M.A.; Dhar, N.R. Study of surface roughness and cutting forces using ANN, RSM, and ANOVA in turning of Ti-6Al-4V under cryogenic jets applied at flank and rake faces of coated WC tool. Int. J. Adv. Manuf. Technol. 2017, 93, 975-991. [CrossRef]

31. Mia, M.; Dhar, N.R. Response surface and neural network based predictive models of cutting temperature in hard turning. J. Adv. Res. 2016, 7, 1035-1044. [CrossRef]

32. Minitab, Inc. Meet Minitab Release 16.1.0 for Windows; Minitab Inc.: State College, PA, USA, 2010.

33. Fnides, B.; Yallese, M.A.; Mabrouki, T.; Rigal, J.F. Application of response surface methodology for determining cutting force model in turning hardened AISI H11 hot work tool steel. Sadhana Acad. Proc. Eng. Sci. 2011, $36,109$. [CrossRef]

34. Srinivasan, A.; Arunachalam, R.M.; Ramesh, S.; Senthilkumaar, J.S. Machining Performance Study on Metal Matrix Composites-A Response Surface Methodology Approach. Am. J. Appl. Sci. 2012, 9, 478-483. [CrossRef]

35. Shoba, C.; Ramanaiah, N.; Nageswara Rao, D. Effect of reinforcement on the cutting forces while machining metal matrix composites-An experimental approach. Eng. Sci. Technol. Int. J. 2015, 18, 658-663. [CrossRef]

36. De Lima, J.G.; De Ávila, R.F.; Abrão, A.M. Turning of hardened AISI 4340 steel using coated carbide inserts. Proc. Inst. Mech. Eng. Part B J. Eng. Manuf. 2007, 221, 1359-1366. [CrossRef]

37. Yousefi, R.; Kouchakzadeh, M.A.; Rahiminasab, J.; Kadivar, M.A. The influence of SiC particles on tool wear in machining of $\mathrm{Al} / \mathrm{SiC}$ metal matrix composites produced by powder extrusion. In Proceedings of the Advanced Materials Research; Trans Tech Publications Ltd.: Zurich, Switzerland, 2011; Volume 325, pp. 393-399.

38. Seeman, M.; Ganesan, G.; Karthikeyan, R.; Velayudham, A. Study on tool wear and surface roughness in machining of particulate aluminum metal matrix composite-response surface methodology approach. Int. J. Adv. Manuf. Technol. 2010, 48, 613-624. [CrossRef]

39. Dabade, U.A.; Sonawane, H.A.; Joshi, S.S. Cutting forces and surface roughness in machining Al/SiCp composites of varying composition. Mach. Sci. Technol. 2010, 14, 258-279. [CrossRef]

40. Pramanik, A.; Zhang, L.C.; Arsecularatne, J.A. Prediction of cutting forces in machining of metal matrix composites. Int. J. Mach. Tools Manuf. 2006, 46, 1795-1803. [CrossRef]

41. Kumar, A.; Mahapatra, M.M.; Jha, P.K. Effect of machining parameters on cutting force and surface roughness of in situ $\mathrm{Al}-4.5 \% \mathrm{Cu} / \mathrm{TiC}$ metal matrix composites. Measurement 2014, 48, 325-332. [CrossRef]

42. Wang, J.; Zuo, J.; Shang, Z.; Fan, X. Modeling of cutting force prediction in machining high-volume SiCp/Al composites. Appl. Math. Model. 2019, 70,1-17. [CrossRef]

43. Morin, E.; Masounave, J.; Laufer, E.E. Effect of drill wear on cutting forces in the drilling of metal-matrix composites. Wear 1995, 184, 11-16. [CrossRef]

44. Kannan, S.; Kishawy, H.A. Effect of tool wear progression on cutting forces and surface quality during cutting metal matrix composites. Int. J. Mach. Mach. Mater. 2008, 3, 241. [CrossRef]

45. Myers, R.H.; Montgomery, D.C.; Anderson-Cook, C.M. Response Surface Methodology: Process and Product Optimization Using Designed Experiments. Technometrics 1996, 38, 285. [CrossRef]

46. Zahia, H.; Athmane, Y.M.; Lakhdar, B.; Tarek, M. On the application of response surface methodology for predicting and optimizing surface roughness and cutting forces in hard turning by PVD coated insert. Int. J. Ind. Eng. Comput. 2015, 6, 267-284. [CrossRef]

47. Mandal, N.; Doloi, B.; Mondal, B.; Das, R. Optimization of flank wear using Zirconia Toughened Alumina (ZTA) cutting tool: Taguchi method and Regression analysis. Measurement 2011, 44, 2149-2155. [CrossRef]

48. Mia, M.; Razi, M.H.; Ahmad, I.; Mostafa, R.; Rahman, S.M.S.; Ahmed, D.H.; Dey, P.R.; Dhar, N.R. Effect of time-controlled MQL pulsing on surface roughness in hard turning by statistical analysis and artificial neural network. Int. J. Adv. Manuf. Technol. 2017, 91, 3211-3223. [CrossRef] 
49. Mia, M.; Bashir, M.A.; Dhar, N.R. Effects of cutting parameters and machining environments on surface roughness in hard turning using design of experiment. In AIP Conference Proceedings; AIP Publishing LLC: Melville, NY, USA, 2016; Volume 1754, p. 60012.

50. Sikder, S.; Kishawy, H.A. Analytical model for force prediction when machining metal matrix composite. Int. J. Mech. Sci. 2012, 59, 95-103. [CrossRef]

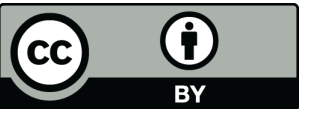

(C) 2020 by the authors. Licensee MDPI, Basel, Switzerland. This article is an open access article distributed under the terms and conditions of the Creative Commons Attribution (CC BY) license (http://creativecommons.org/licenses/by/4.0/). 